\title{
DECREASED MORBIDITY AND MORTALITY FROM INTESTINALASCARIASIS: EXPERIENCE OF A SINGLE CENTER
}

\author{
MAH BHUIYAN ${ }^{1}$, TK CHOWDHURY $^{2}$, MAA FAROOQ ${ }^{1}$, MM SAJID ${ }^{1}$, MAM RAHMAN $^{1}$, MM HOQUE$^{1}$, \\ KA SARWAR ${ }^{1}, M^{\prime} K A B I R^{3}$, T BANU $^{4}$.
}

\begin{abstract}
:
Background: Ascariasis is a common gastrointestinal infestation worldwide. It affects more children who live in poor hygenic condition. Pediatric surgeons are supposed to manage related surgical complications of ascariasis. Objective: To evaluate the recent pattern of occurrence of intestinal and biliary ascariasis with morbidity and mortality related to it. Materials and Methods: Study design: Retrospective study. Period of study: Study was conducted between Jan 2006 - Dec 2011 (total 06 years). Place of study: This study was carried out in the department of Pediatric Surgery.Chittagong Medical College Hospital ( $\mathrm{CMCH})$, Chittagong; Bangladesh. Study Subjects: Patients admitted and diagnosed as intestinal (1591) and biliary (181) ascariasis in the department of Pediatric surgery, $\mathrm{CMCH}$ were evaluated. Results: A total of 1772 patients were admitted with surgical complication of ascariasis. Among them $1591(89.78 \%)$ patients were diagnosed as intestinal ascariasis and $181(10.22 \%)$ patients as biliary ascariasis. Age range was 6 months to 12 years with mean age of 6 years for intestinal ascariasis. Biliary ascariasis presented between 3 years to 12 years with mean age of 7 years. Male (1060) suffered more than female (531) . Male to female ratio was 2:1 for intestinal ascariasis

1. Dr. Md. Akbar Husain Bhuiyan, Dr. Md. Abdullah Al Farooq, Dr. Md. Minhajuddin Sajid, Dr. MA Mushfiqur Rahman, Dr. Md. Momtazul Hoque, Dr. Khurshid Alam Sarwar, Assistant Professor, Pediatric Surgery Chittagong Medical College, Chittagong

2. Dr. Tanvir Kabir Chowdhury, Post graduate student, Pediatric Surgery Chittagong Medical College, Chittagong

3. Dr. Mahfuzul Kabir, Registrar, Pediatric Surgery Chittagong Medical College, Chittagong

4. Prof. Tahmina Banu, Professor and head, Pediatric Surgery Chittagong Medical College, Chittagong

Correspondence: Dr. Md. Akbar Husain Bhuiyan, Assistant Professor, Department of Pediatric Surgery, Ward-11B, Chittagong Medical College \& Hospital, Chittagong 4000, Bangladesh. E-mail: akbarbeverly@yahoo.com
\end{abstract}

while females (120) suffered more than male(61) in biliary ascariasis ( ratio 2: 1). Total 231 surgery both elective and emergencies were done. Discussion: Most of the patients $(52-81 \%)$ were treated by endoscopic removal of worm from common bile duct. Some patients $(15-31 \%)$ were treated successfully by conserevative approach. Only a few patients needed open surgical procedure. No patient had died from biliary ascariasis and death from complications of intestinal ascariasis reduced from $20 \%$ to $4 \%$ over the last 6 years. Conclusion: There has been a reduced number of disease burden over the last few years from ascariatic and biliary ascariasis.

Key Words: Ascariasis, Intestinal obstruction, Biliary Ascariasis.

\section{Introduction:}

Ascariasis (Ascaris lumbricoides infestation) is the most common helminthic infestation in the world with an estimated worldwide prevalence of $25 \%^{1,2}$. In Bangladesh the prevalence of infection ranged from $64 \%$ to $95 \%$ and mean worm burdens ranged from 7 to 23 worms $^{3}$. It affects mainly children of low income group whose standard of public health and personal hygiene are at the lowest ${ }^{4}$. The worms may live in the intestine without causing apparent harm. When they move to the orifices, ducts and cavities or form a mass, dangerous complications may arise ${ }^{5}$. Complications of ascariasis include intestinal obstruction, biliary obstruction, pancreatitis, appendicitis and primary peritonitis . Intestinal obstruction is the most common form ${ }^{4}$. In 2001, the World health assembly endorsed a strategy for the control of geohelminth infestations and associated morbidity through the regular treatment of high-risk groups, particularly school-age children ${ }^{6}$. In line with these, national governments and donor organisations have prioritized anthelmintic 
treatment programs for school-age children? Bangladesh had a $87 \%$ national coverage of anthelmintic for $1-5 \mathrm{yrs}$ old in 2011 with $86 \%$ rural and $81 \%$ urban coverage ${ }^{8}$. Today, surgical complications related to ascariasis infestation seems to be reducing because of the common use of anthelmintic agents and the success of the medical treatment. We feel interest o evaluate the recent pattern of occurrence of intestinal and biliary ascariasis and evaluate the morbidity and mortality related to it.

\section{Materials and Methods:}

Study design: Retrospective studyPeriod of study: Jan 2006- Dec 2011 ( total 06 years)Place of study: In the department of Pediatric Surgery, Chittagong Medical College Hospital (CMCH), Chittagong; Bangladesh. Study Subjects: Patients admitted and diagnosed as intestinal and biliary ascariasis in the department of Pediatric Surgery, CMCH. A total of 1772 patients fullfilled the criteria. Among them 1591 patients had suffered from intestinal ascariasis and 181 patients suffered from biliary ascariasis.

Data Collection: Hospital records of patients diagnosed as intestinal ascariasis and biliary ascariasis were evaluated retrospectively. Help was also taken from yearly departmental audits of 2006 to 2011. Record file of each patient was scrutinized to check history, clinicla findings and investigations including abdominal X-ray, USG, Endoscopy etc.) to ascertain whether the diagnosis fit well or not. Adequacy of conservative treatment and proper indication of surgical treatment were noted. Outcome including morbidity, mortality and complications were evaluated. Yearly total number of patients were calculated. Yearwise data were compiled and compared with these. Inadequate and incomplete patients' record were not considered for further evaluation. Data were evaluated to see the yearly percentage of patient bulk, treatment, surgical intervention and outcome.

\section{Results:}

Of the 12754 patients of various diseases admitted in the department of Pediatric Surgery, Chittagong Medical College Hospital during the 6 year period (Jan 2006-Dec 2011), 1772 (13.89\%) patient were diagnosed as suffered from ascariatic surgical complications. Among them 1591 (89.78\%) patients were diagnosed as intestinal ascariasis and 181 $(10.22 \%)$ patients as biliary ascariasis. Age range was 6 months to 12 years with mean age of 6 years for intestinal obstruction. Biliary ascariasis presented between 3 years to 12 years with mean age of 7 years. Male (1060) suffered more than the female (531) from intestinal ascariasis (Male : Female 2:1), while the female (120) suffered more than male (61) in biliary ascariasis ( ratio 2:1). After clinical evaluation, USG and endoscopy were done to confirm the diagnosis of biliary ascariasis. Percentage of endoscopically diagnosed biliary ascariasis rose from $17 \%$ to $37 \%$ with sonographic diagnosis ranged between $39 \%$ to $78 \%$ during the study period. Most of the patients $(52 \%-81 \%)$ were treated by endoscopic removal of worm from common bile duct. Some patients ( $15 \%-31 \%$ ) were treated successfully by conserevative approach. Only a few patients $0.04 \%$ $0.51 \%$ needed open surgical procedure in case of biliary ascariatic obstruction and $5 \%$ to $1 \%$ in case of ascariatic intestinal obstruction in respect to total operation yearwise. There was no death from the complications of biliary ascariasis and death from the complication of intestinal ascariasis reduced from $20 \%$ to $4 \%$ over the last 6 years.

Total number of patient admitted increased from 2006 to 2011 (1550-2985) but patients diagnosed as intestinal ascariasis did not increassed that much (from 246-298), rather percentage of intestinal ascariasis declined (16\% to $8 \%$ ). Out of ascariatic obstruction, partial obstruction increased from $50 \%$ to $75 \%$ but complete obstruction decreased from $50 \%-25 \%$. Ascariatic biliary obstruction decreased from $2 \%$ to $1 \%$.

Table - I

Yearly number and percentage of patients suffered from intestinal and biliary ascariasis

\begin{tabular}{lcccccc}
\hline Years of study & 2006 & 2007 & 2008 & 2009 & 2010 & 2011 \\
\hline Yearly total admitted patients & 1550 & 1652 & 1935 & 2162 & 2470 & 2985 \\
1. Total number of intestina & $246(16 \%)$ & $255(15 \%)$ & $257(13 \%)$ & $284(13 \%)$ & $298(12 \%) 251(8 \%)$ \\
I ascariasis with percentage (\%) & & & & & \\
Partial Obstruction with \% & $123(50 \%)$ & $136(53 \%)$ & $155(60 \%)$ & $195(68 \%)$ & $214(72 \%) 187(75 \%)$ \\
Complete obstruction with \% & $123(50 \%)$ & $119(47 \%)$ & $102(40 \%)$ & $89(32 \%)$ & $84(28 \%)$ & $64(25 \%)$ \\
2. Total number of biliar & $29(2 \%)$ & $38(2 \%)$ & $26(1 \%)$ & $27(1 \%)$ & $26(1 \%)$ & $35(1 \%)$ \\
y ascariasis with percentage (\%) & & & & & & \\
\hline
\end{tabular}


Table -II

Surgery done for intestinal ascariasis in comparison to total surgery

\begin{tabular}{lcccccc}
\hline & 2006 & 2007 & 2008 & 2009 & 2010 & 2011 \\
\hline Total operations & 980 & 1296 & 1724 & 1879 & 1456 & 2420 \\
Emergency operations & 399 & 469 & 570 & 640 & 605 & 838 \\
Surgery for intestinal ascariasis & 51 & 46 & 45 & 40 & 26 & 23 \\
Percentage of total surgery & $5 \%$ & $3.5 \%$ & $2.6 \%$ & $2 \%$ & 1.7 & $1 \%$ \\
Percentage of Emergency Surgery & $13 \%$ & $10 \%$ & $8 \%$ & $6 \%$ & $4 \%$ & $3 \%$ \\
- Milking of gut & $5(10 \%)$ & $4(9 \%)$ & $5(11 \%)$ & $3(8 \%)$ & $3(12 \%)$ & $2(9 \%)$ \\
- Intestinal resection withAnastomosis & $28(55 \%)$ & $26(56 \%)$ & $25(56 \%)$ & $26(65 \%)$ & $16(62 \%)$ & $17(74 \%)$ \\
- Ileostomy & $18(35 \%)$ & $16(35 \%)$ & $15(33 \%)$ & $11(28 \%)$ & $7(27 \%)$ & $4(17 \%)$ \\
\hline
\end{tabular}

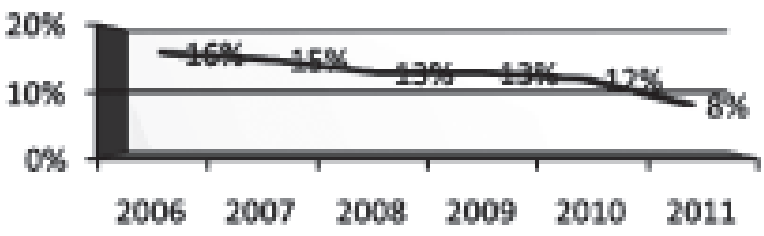

Fig.1: Yearly percentage of admitted patients of intestinal ascariasis compared with total admitted patients.

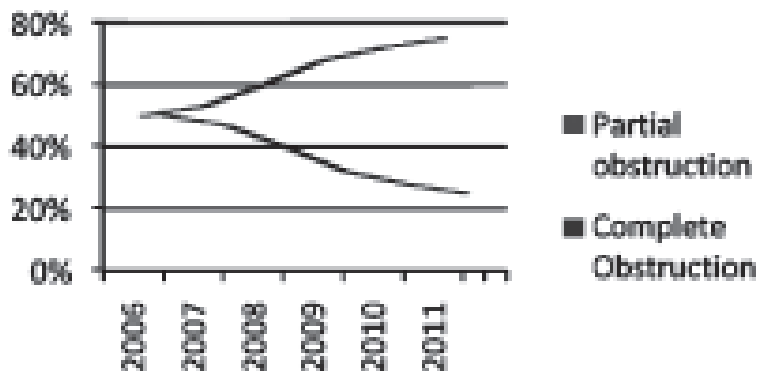

Fig.-2: Percentage of partial and complete intestinal obstruction . Out of the ascariatic obstruction, partial obstruction increased from $50 \%$ to $75 \%$ but complete obstruction decreased from $50 \%-25 \%$.

\section{Percentage of biliaryascariasis}

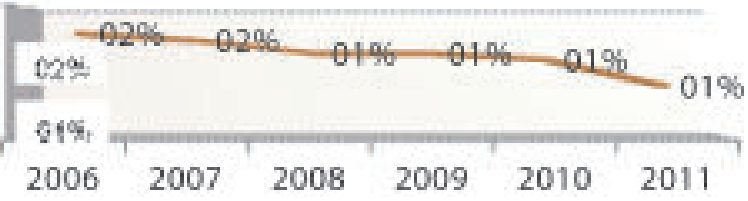

Fig.-3: Yearly percentage of ascariatic biliary obstruction. Ascariatic biliary obstruction decresd from $2 \%$ to $1 \%$ for the last 6 years

A total of 9755 operations were done for various diseases during this period and of these 3521 (36\%) were emergency operations. Two hundred and thirty

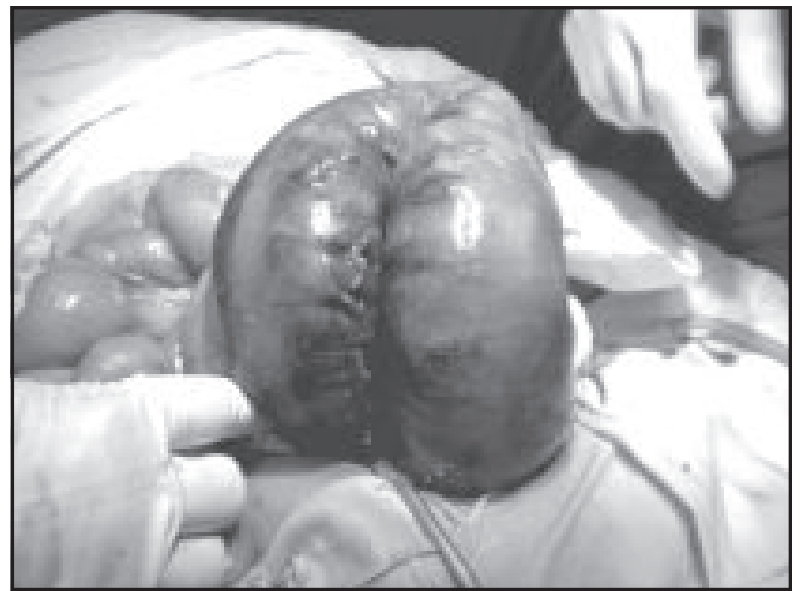

Fig.-4: Gangrenous gut due to volvulous by worm bolus followed by resection and anastomosis.

one (231) surgery were done for intestinal ascariasis which is $2.37 \%$ of total surgery and $6.56 \%$ of the emergency surgeries done during this period. Percentage of ileostomy declined from 35\% - 17\% but the frequency of resection-anastomosis increased from $55 \%-74 \%$. Milking of the gut to relieve obstruction remained almost steady $(8 \%-12 \%)$ during the study period.

Resection and anastomosis is noted to be the commonest surgical procedure performed for intestinal ascariasis. lleostomy is the next common procedure that performed and milking of the gut is the least of all performed procedure. Percentage of ileostomy declined but the frequency of resection-anastomosis increased. Milking of the gut remained almost steady during the study period.

Percentage (\%), of endoscopically diagnosed biliary ascariasis rose from $17 \%$ to $37 \%$ with sonographic diagnosis ranged between $39 \%$ to $78 \%$ during the study period are shown in Table-III. 
Table-III

USG and upper GI endoscopy performed to diagnose biliary ascariasis

\begin{tabular}{lllllll}
\hline Investigation & 2006 & 2007 & 2008 & 2009 & 2010 & 2011 \\
\hline USG with percentage (\%) & $39 \%$ & $44 \%$ & $41 \%$ & $67 \%$ & $73 \%$ & $78 \%$ \\
Endoscopy with percentage (\%) & $17 \%$ & $23 \%$ & $28 \%$ & $31 \%$ & $34 \%$ & $37 \%$ \\
\hline
\end{tabular}

Table- IV

Treatment given for patient suffering from biliary ascariasis

\begin{tabular}{lcccccc}
\hline Year & 2006 & 2007 & 2008 & 2009 & 2010 & 2011 \\
\hline Total operation & 980 & 1296 & 1724 & 1879 & 1456 & 2420 \\
Toatal patient & 29 & 38 & 26 & 27 & 26 & 35 \\
Treated successfully by & & & & & & \\
Conservative (\%) & $9(31 \%)$ & $11(29 \%)$ & $4(15 \%)$ & $5(19 \%)$ & $4(15 \%)$ & $8(23 \%)$ \\
Endoscopic (\%) & $15(52 \%)$ & $21(55 \%)$ & $19(73 \%)$ & $20(74 \%)$ & $21(81 \%)$ & $26(74 \%)$ \\
$\%$ of total surgery & $5(0.51 \%)$ & $6(0.46 \%)$ & $3(0.17 \%)$ & $2(0.10 \%)$ & $1(0.06 \%)$ & $1(3 \%)$ \\
\hline
\end{tabular}

In Table-IV, it has been shown that the most of the patients were treated by endoscopic removal of worm from common bile duct ( $52 \%-81 \%$ ). Some patients were treated successfully by conserevative approach $(15 \%-31)$. Only few patients needed open surgical procedure $(0.04 \%-0.05 \%$ in case of biliary ascariasis in respect to total operation yearwise ) to remove worm when both the above mentioned measures failed and percentage of total surgery in intestinal ascariatic obstruction was $1 \%$ to $5 \%$ (out of total operation yearwise).

Death review showed that no patient died from biliary ascariasis. Death from intestinal ascariasis reduced drammatically from $20 \%$ to $4 \%$ of total yearly deaths for the last 5 years is shown in Table - $V$.

\section{Discussion:}

Ascariasis (Ascaris lumbricoides infestation) is the most common helminthic infestation in the world with an estimated worldwide prevalence of $25 \%^{1,2}$. Ascariasis has been recorded since Hippocrates' time ${ }^{9}$. It has been one of man's companion probably since the beginning of domesticating pigs ${ }^{10}$. It affects primarily children, especially those who live in low socioeconomic condition and those with malnutrition and immune deficiencies ${ }^{9}$. The playing of children on polluted ground near their homes, tracking of pollution into the houses, and eating with dirty hands are some of the most important factors in the epidemiology. ${ }^{10}$ World wide 20,000 deaths per year occur due to this ${ }^{11}$ . In Bangladesh the prevalence of infestation ranged from $64 \%$ to $95 \%{ }^{12}$ and mean worm burdens ranged from 7 to 23 worms $^{3}$. Passage of worms in the stools or vomitus, or the formation of an entangled bolus of worms occurs at the intestine ${ }^{13}$. Obturation and mechanical obstruction may occur at the level of ileocecal valve, where ascaris may excrete neurotoxins that make the small bowel contract (spasticty) resulting in colicky pain. It has been suggested that administration of single heavy-dose anthelmintics at this stage may prevent spontaneous resolution of the entangled bolus of worms and may precipitate complete intestinal obstruction. ${ }^{14}$ The migration and formation of worms' mass in the intestinal lumen is felt by the host as abdominal mass and abdominal colic, and partial intestinal obstruction may develop. Obstruction may be the result of associated volvulus or invagination (intussusception) caused by the bolus of worms. There are reports of hematemesis ${ }^{15}$, encephalopathy ${ }^{17}$ due to ascaris . The worms may live in the intestine without causing apparent harm. When they move to the orifices, ducts and cavities or form a mass, dangerous complications may arise ${ }^{5}$. Complications of ascariasis include intestinal obstruction, biliary obstruction, pancreatitis ${ }^{16}$, appendicitis and primary peritonitis . Intestinal obstruction is the most common form ${ }^{4}$. Intestinal obstruction may be partial or complete and treated conservatively or surgically. ${ }^{1}$

Biliary and pancreatic ascariasis may be associated with biliary colic, acute cholangitis, obstructive jaundice, choledocholithiasis, acute pancreatitis, 
acute cholecystitis, liver abscess, hepatolithiasis , stricture of common bile duct, pancreatic abscess and cirrhosis of liver ${ }^{18}$. Biliary ascariasis with dead worms is more dangerous than that with living worms ${ }^{18}$ and endoscopic or surgical intervention may be required repeatedly in those with dead worms ${ }^{18}$.

In 2001, the World health assembly endorsed a strategy for the control of geohelminth infestations and associated morbidity through the regular treatment of high-risk groups, particularly school-age children ${ }^{6}$.In line with these, national governments and donor organisations have prioritized anthelmintic treatment programs for school-age children ${ }^{7}$. Bangladesh had a $87 \%$ national coverage of anthelmintic for $1-5 \mathrm{yrs}$ old in 2011 with $86 \%$ rural and $81 \%$ urban coverage ${ }^{8}$. With those efforts, surgical complications related to ascariasis infestation seems to be reducing because of the common use of anthelmintic agents and the success of the medical treatment.

During the study period ( Jan 2006-Dec 2011, 6 years) 12754 patient was admitted in the department of Pediatric surgery $\mathrm{CMCH}$. It was found that 1772 $(13.89 \%)$ patient had been suffering from ascariasis. Among them 1591 (89.78\%) patients were diagnosed as intestinal ascariasis and $181(10.22 \%)$ patients as biliary ascariasis. Age range was 6 months to 12 years with mean age of 6 years for intestinal obstruction. Biliary ascariasis presented between 3 years to 12 years with mean age of 7 year. Male (1060) suffered more than the female (531) from intestinal ascariasis (Male : Female 2:1), while the female (120) suffered more than male (61) in biliary ascariasis ( ratio $2: 1$ ). Total number of admitted patient in Pediatric surgery increased from 2006 to 2011 (1550-2985) but patients diagnosed as intestinal ascariasis did not increased that much (from 246-298), rather percentage of intestinal ascariasis declined (16\% to $8 \%)$. Out of ascariatic obstruction, partial obstruction increased from $50 \%$ to $75 \%$ but complete obstruction decreased from 50\%- 25\%. Ascariatic biliary obstruction decresd from $2 \%$ to $1 \%$. A total of 9755 operations were done for various diseases during this period and of these 3521 (36\%) were emergency operations. Two hundred and thirty one ( 231 ) surgery were done for intestinal ascariasis which is $2.37 \%$ of total surgery and $6.56 \%$ of the emergency surgeries done during this period. Resection and anastomosis is noted to be the commonest surgical procedure performed for intestinal ascariasis. lleostomy is the next common procedure that had performed and milking of the gut is the least of all performed procedure. Percentage of ileostomy declined from 35\% - 17\% but the frequency of resection-anastomosis increased from $55 \%-74 \%$. Milking of the gut to relieve obstruction remained almost steady $(8 \%-12 \%)$ during the study period. After clinical evaluation, USG and endoscopy were done to confirm the diagnosis of biliary ascariasis. Percentage (\%), of endoscopically diagnosed biliary ascariasis rose from $17 \%$ to $37 \%$ with sonographic diagnosis ranged between $39 \%$ to $78 \%$ during the study period .

Most of the patients were treated by endoscopic removal of worm from common bile duct ( $52 \%-81 \%$ ). Some patients were treated successfully by conserevative approach (15\% -31\%). Only few patients needed open surgical procedure $(0.04 \%-0.51 \%)$ to remove worm (in case of biliary ascariasis and in respect to total operation yearwise), when both the above mentioned measures failed. Endoscopic removal of worm gradually increased in number ( $52 \%$ $81 \%)$. Surgical intervention reduced gradually in the following years $0.051 \%$ to $0.04 \%$, in case of biliary ascariatic obstruction and in case of intestinal ascariatic obstruction, it was reduced from $5 \%$ to $1 \%$ yearwise in respect to total operation.Death review showed that no patient died from biliary ascariasis. Death from intestinal ascariasis reduced drammatically from $20 \%$ to $4 \%$ of total yearly deaths for the last 6 years. Decreasing number of intestinal and biliary ascariasis has been found in the study. The regular anthelmintic program have played a good role in this reduction. There has been an increased number of sonologically and endoscopically diagnosed biliary ascariasis probably due to increased availability and practice of this procedure. Overall morbidity related to intestinal and biliary ascariasis has been reduced. Death from intestinal ascariasis reduced that signifies the improvement of total management of these patients.

\section{Conclusion:}

Intestinal and Biliary ascariasis is still a major concern for our health. Recently there has been gradual reduction in terms of number of cases and complications. Routine anthelmintic campaign for 1 5 yrs old children played a major role in this improved scenario. There has been a reduced number of disease burden over the last few years from ascariatic and 
biliary ascariasis. Diagnosis has improved with increased avalability of ultrasonography and endoscopy. Overall morbidity declined from both the diseases. Number of death reduced in intestinal ascariasis but no death was noted from biliary ascariasis.

\section{References :}

1. Management of Intestinal Obstruction Caused by Ascariasis. A. Bedii Salman. Jourrnal \&Pediatric Surgery, 1997; 32(4): pp 585-87

2. Soil-transmitted helminth infections: ascariasis, trichuriasis, and hookworm. Bethony J, Brooker S, Albonico M, et al. Lancet. 2006; 367(9521): 1521-32.

3. The distribution of Ascaris lumbricoides in human hosts: a study of 1765 people in Bangladesh . Hall A, Anwar KS, Tomkins A, Rahman L. Trans R Soc Trop Med Hyg. 1999; 93(5): 503-10.

4. Intestinal complications of round worms in children. Sorendran N, Paulose MO: J Pediatr Surg 1988; 23: 931-35.

5. Surgical manifestations of Ascaris lumbricoides in the intestine. Cole GJ: Br J Surg 1965; 52: 444-47.

6. WHO. World Health Assembly Resolution 54.19. Schistosomiasis and soil-transmitted helminth infections. May 21, 2001: (http://www.who.int/ wormcontrol/about_us/en/ea54r19.pdf)

7. Soil-transmitted helminthiasis. Savioli L, Albonico, M. Nature Rev Microbiol 2004; 2: 61819.

8. Health Bulletine 2011. Government of people's republic of Bangladesh, Ministry of health and familty welfare.Page -43.( http://dghs.gov.bd/ dmdocuments/HealthBulletin2011.pdf)

9. Ascaris Lumbricoides Infestation as a Cause of Intestinal Obstruction in Children: Experience
With 87 Cases .Enrique Villamizar, Mizrahinn Mendez, Efraim Bonilla, Humbet-to Varon et al. Journalof Pediatric Surgery. 1996: 31(1): pp 20105

10. Ascariasis .Banglapedia-National encyclopedia of Bangladesh. (www.banglapedia.) Accessed on 22.02.2012

11. Selective primary health care: An interim strategy for disease control in developing countries. Walsh JA, Warren KS. N Engl J Med 1979;301:967-74

12. The prevalence and intensity of Ascaris lumbricoides infections in Moslem children from northern Bangladesh.Martin J, Keymer A, Isherwood RJ, Wainwright SM. Trans R Soc Trop Med Hyg. 1983;77(5):702-6.

13. Surgical complications of ascariasis. Ochoa B. World J Surg 1991; 15: 222-27.

14. Intestinal obstruction due to ascaris. Report of thirty-one cases. Jenkins MO, Beach MW: Pediatrics 1954; 13: 419-425.

15. Massive Gastrointestinal Bleeding in Infants with Ascariasis . Surasak Sangkhathat, Sakda Patrapinyokul, Prasit Wudhisuthimethawee, Jerawan Chedphaopan, Winyou Mitamun. Journal of Pediatric Surgery, 003; 38(11): pp 1696-98

16. Recurrent pancreatitis secondary to pancreatic ascariasis. Lee K H, Shelat V G, Low H C, Ho K Y, Diddapur R K. Singapore Med J 2009; 50(6) : 218

17. A rare manifestation of ascariasis: Encephalopathy. Mukadder $A y^{\circ}$ e Selimogilu, Candan Ferai Öztürk, Vildan Ertekin. The Journal of Emergency Medicine. 2005; 28(1): 87-88

18. Comparative study on presentation of biliary ascariasis with dead and living worms. Alam S, Mustafa G, Rahman S, Kabir SA, Rashid HO, Khan M. Saudi J Gastroenterol 2010;16:203-6. 